\title{
КОНВЕНЦИЯ СОВЕТА ЕВРОПЫ О ЗАЩИТЕ ФИЗИЧЕСКИХ ЛИЦ ПРИ АВТОМАТИЗИРОВАННОЙ ОБРАБОТКЕ ПЕРСОНАЛЬНЫХ ДАННЫХ
}

\begin{abstract}
Аннотация: В настоящей статье, написанной на основе реферата, подготовленного по итогам обучения на факультативе по курсу «Безопасность предпринимательской деятельности», рассматриваются принципиальные вопросы защиты прав личности при автоматизированной обработке ее персональных данных. Рассматривая законодательство Европейского Союза и Российской Федерации в данной области, автор обращает внимание на одно из важнейших направлений в современной правоприменительной практике защиты персональных данных физических лии от их неправомерного использования и разглашения. Ключевые слова: Юриспруденция, защита, персональные данные, неправомерное разглашение, конвенция Совета Европь, Российская Федераџия, ратификачия, Роскомнадзор, технические регламентыл, ограничения
\end{abstract}

\section{Введение}

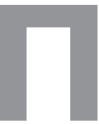
роблема защиты персональных данных физических лиц остро стоит перед мировым сообществом, пожалуй, столько лет, сколько лет существует само человечество. В современном мире право физического лица на личную тайну закреплено конституциями всех развитых государств ${ }^{1}$. Суть этого права заключается в следующем: только сам человек, владеющий некими сведениями о себе, вправе решать, подлежат они разглашению или нет. Законодательством большинства стран мира установлен также перечень субъектов, которые вправе требовать от лица разглашения персональных данных. В случае неправомерного разглашения таких сведений их владелец имеет право на защиту своих нарушенных интересов, при этом меры ответственности причинителя вреда не всегда ограничиваются гражданско-правовой ответственностью. В ряде стран, в том числе в России, неправомерное разглашение персональных данных определенного характера является уголовным преступлением.

Федеральный закон о ратификации Конвенции 1981 года Президент РФ подписал 19 декабря 2005 года, возложив на Российскую Федерацию обязательства по приведению в соответствие с нормами европейского законодательства деятельность в области защиты прав субъектов персональных данных (далее - ПДн). Первым шагом в реализации взятых обязательств стало принятие

${ }^{1}$ Конституция Российской Федерации.
Федерального закона № 152-ФЗ от 27.07.2006 г. «О персональных данных»². Закон вступил в силу в январе 2007 года. Закон № 152 ФЗ определил высокоуровневые требования, которые затем были конкретизированы в подзаконных актах Правительства РФ и Министерства связи, нормативно методических документах регуляторов Федеральной службы по техническому и экспортному контролю (ФСТЭК России), Федеральной службы безопасности Российской Федерации (ФСБ России) и Федеральной службы по надзору в сфере связи и массовых коммуникаций (Роскомнадзор). Каждый из этих актов и документов посвящен отдельным областям и тематикам законодательства.

\section{Предпосылки принятия Конвенции}

Анализ исторических корней проблемы защиты персональных данных отсылает нас к 450 году до н.э. - Закону 12 таблиц, именно в классическом Римском праве впервые появились положения о защите чести. За периоды Средневековья и Нового времени положение обрело новый смысл и в 18 веке нашло отражение в Швейцарии, где гарантировалась защита права имени и портрета. Базовые принципы защиты прав человека и гражданина были сформированы уже к концу 19 века: в европейских государствах они были обозначены как право защиты «секретной сферы», а в США как право зашиты частной жизни.

\footnotetext{
2 Федеральный закон № 152-Ф3 «О защите персональных данных».
} 


\section{Национальная безопасность $1(24) \cdot 2013$}

В 20 веке ситуация с соблюдений прав личности ухудшилась, поэтому 10 декабря 1948 года Генеральная Ассамблея ООН принимает Всеобщую Декларацию прав человека ${ }^{3}$, где был закреплен принцип о том, «что никто не может подвергаться произвольному вмешательству в личную и семейную жизнь человека, произвольным посягательствам на неприкосновенность жилища, тайну его корреспонденции или на его честь и репутацию». Развитие этот принцип получил в принятой Советом Европы 4 ноября 1950 года «Конвенции о защите прав человека и основных свобод».

Следующим шагом законодателей стали локальные акты в связи с появлением ЭВМ и, соответственно, новых технологий обработки и хранения данных ${ }^{4}$. Поэтому в 1974 году в США принимается закон «О правах личности» (The Privacy Protection Act of 1980), а уже в 1981 году Советом Европы была разработана и принята Конвенция «О защите прав физических лиц в отношении автоматизированной обработки персональных данных» (далее - Конвенция) ${ }^{5}$. Область действия Конвенции распространяется на «персональные файлы данных» и «автоматизированную обработку персональных данных» в общественном и частном секторе. Главной причиной разработки Конвенции явилась необходимость упорядочивания законодательства европейских стран, поэтому в 1981 году Еврокомиссией были опубликованы рекомендации для государств - членов ЕС о принятии соглашений об использовании Конвенции.

После принятия Конвенции стало понятно, что ее ратификация в ряде стран вызовет значительные затруднения, в первую очередь из-за противоречия локальных актов и технической неподготовленности. И уже в 1995 году была разработана и принята Директива 95/46/EC «О защите физических лиц применительно к обработке персональных данных и свободном движении таких данных». Основная ее цель - создание единого внутреннего рынка, и теперь государствам - членам ЕС должны были реализовать ее условия к концу 1998 года.

Следующее поколение законодательства о персональных данных представлено в Европе Директивой 2002/58/ЕС «Об обработке персональных данных и защите конфиденциальности и личной тайны в сфере электронных коммуникаций». Главная ее цель - обе-

\footnotetext{
${ }^{3}$ Всеобщая декларация прав человека.

${ }^{4}$ Слепов О. Защита персональных данных/Jet Info № 5.

${ }^{5}$ Конвенция Совета Европы.
}

спечение права на самоопределение человека при автоматизированной обработке его персональных данных в условиях глобализации современного мира, когда границы, по сути, стерты. Здесь говорится о минимизации распространения персональных данных в пользовательских сетях и их анонимности в такой степени, в какой это возможно 6 .

США, Великобритания и Канада, так же как и Россия, разработали технические регламенты, которые транслируют положения законодательства верхнего уровня в конкретные советы и рекомендации по защите персональных данных. В Великобритании в 1998 году был принят «Закон о защите персональных данных» - «Data Protection Act 1998». Его техническая реализация - проект стандарта «Specification for the management of personal information in compliance with the Data Protection Act 1998» (BS 10012) получил статус официального документа в июне 2009. Параллельно с англичанами свою версию стандарта по безопасности ПДн выпустили в США. Проект документа по защите персональных данных для американских государственных структур - «Guide to Protecting the Confidentiality of Personally Identifiable Information (PII)» (SP 800122) регламентирует выполнение Законов «The Privacy Act of 1974» и «Privacy Protection Act of 1980». Канада выпустила «Privacy Code» - набор документов для реализации законодательства по защите сведений о частных лицах (The Privacy Act и PIPEDA). Канадский, английский и американский стандарты, в отличие от документов российских регуляторов, дают более общие рекомендации по обеспечению безопасности ПДн и не предписывают, как конкретно должны защищаться персональные данные. Более того, тот же американский стандарт рекомендует по возможности обезличивать персональные данные, чтобы уйти от различных защитных мер, снижающих удобство пользования информацией.

\section{Анализ положений Конвенции}

Вопрос о необходимости охраны и защиты персональных данных не вызывает сомнений. Однако все чаще юристы, специализирующиеся на регулировании различных аспектов информационного обмена, сталкиваются с практикой рассмотрения споров о неправомерном разглашении персональных

\footnotetext{
${ }_{6}^{6}$ Волков А. Персональные данные: от Европы до России/ ibuisness.
} 
данных физических лиц. Этим объясняется постановка новой задачи перед законодателями: какими должны быть конкретные меры по охране и защите персональных данных?

С середины 70-х годов в развитых государствах для обработки документов, в том числе содержащих персональные данные, стали применяться, как было сказано выше, компьютерные технологии. В наши дни все чаще для передачи данных используются глобальные информационные сети, самой распространенной из которых является сеть Интернет. «Бумажный» документооборот постепенно заменяется электронным. Однако официально электронный документооборот узаконен всего в нескольких странах мира. После принятия соответствующих законов в США, Японии, Германии, Италии узаконили электронный документооборот некоторые страны бывшего СССР - в частности, Украина, Узбекистан и Казахстан. Отсутствие в национальном законодательстве большинства государств четко определенных правил сбора, обработки, передачи и хранения документов, содержащихся на электронных носителях, привело к разработке соответствующих международных соглашений.

Детально нами будут рассмотрены положения Конвенции 1981 года7. Каковы основные положения Конвенции, касающиеся принципов защиты физических лиц от неправомерного обращения с их персональными данными? В соответствии со ст. 5 Конвенции, персональные данные, подвергающиеся автоматизированной обработке:

a) собираются и обрабатываются на справедливой и законной основе;

б) хранятся для определенных и законных целей и не используются иным образом, несовместимым с этими целями;

в) являются адекватными, относящимися к делу и не чрезмерными для целей их хранения;

г) являются точными и, когда это необходимо, обновляются;

д) сохраняются в форме, позволяющей идентифицировать субъекты данных, не дольше, чем это требуется для целей хранения этих данных.

При этом есть определенные категории персональных данных, которые в принципе не могут подвергаться автоматизированной обработке, если внутреннее законодательство не устанавливает соответствующих гарантий (ст. 6 Конвенции).

\footnotetext{
${ }^{7}$ Конвенция Совета Европы
}

Иными словами, определенные сведения о человеке должны охраняться особенно тщательно, поэтому электронные средства их обработки, как недостаточно надежные, исключаются. Это персональные данные, касающиеся:

- $\quad$ расовой принадлежности;

- политических взглядов или религиозных, или других убеждений;

- здоровья или половой жизни;

- судимости физического лица.

Следующий вопрос, ответ на который необходимо знать каждому субъекту, имеющему дело с автоматизированной обработкой персональных данных - вопрос о применяемых средствах и мерах защиты этих данных. Меры безопасности, применяемые для защиты персональных данных, хранящихся в автоматизированных базах данных, должны быть направлены на предотвращение их случайного или несанкционированного уничтожения или случайной потери, а также на предотвращение несанкционированного доступа, их изменения или распространения таких данных (ст. 7 Конвенции).

При этом владельцу персональных данных предоставляется ряд дополнительных гарантий. Так, ст. 8 Конвенции предусматривает, что любому лицу (имеется в виду физическое лицо - владелец персональных данных) должна быть предоставлена возможность:

a) знать о существовании автоматизированной базы персональных данных, знать ее основные цели, а также название и место нахождения администратора базы данных;

б) получить через разумный промежуток времени и без чрезмерной задержки или чрезмерных расходов подтверждение того, хранятся ли касающиеся его персональные данные в автоматизированной базе данных, а также получить такие данные в доступной для понимания форме;

в) добиваться в случае необходимости исправления или уничтожения таких данных, если они подвергались обработке в нарушение норм внутреннего законодательства, воплощающего основополагающие принципы защиты персональных данных;

г) прибегать к средствам правовой защиты в случае невыполнения просьбы о подтверждении или в случае необходимости о предоставлении данных, их изменении или уничтожении.

И наконец, допустимы ли изъятия из режима персональных данных, когда такие данные могут быть правомерно разглашены без согласия их владельца? 


\section{Национальная безопасность $1(24) \cdot 2013$}

Статья 9 Конвенции содержит закрытый перечень случаев, когда возможно отступление от провозглашенных Конвенцией основополагающих принципов охраны и защиты персональных данных. Такое отступление допускается, когда оно предусмотрено внутренним законодательством государства-участника Конвенции и является необходимой в демократическом обществе мерой, принимаемой в интересах защиты безопасности государства, общественной безопасности, валютно-кредитных интересов государства или пресечения уголовных преступлений, а также защиты владельца персональных данных или прав и свобод других лиц. Кроме того, внутреннее законодательство государства-участника может предусматривать ограничения на осуществление прав на охрану и защиту персональных данных в отношении автоматизированных баз персональных данных, используемых для целей статистики или научных исследований, когда явно отсутствует какойлибо риск нарушения неприкосновенности частной жизни владельцев данных.

Безусловно, положения главы отвечают интересам физических лиц - владельцев персональных данных, правам и свободам любой личности, а также общедемократическим ценностям. Однако положения главы изобилуют неопределенными правилами работы с персональными данными в автоматизированных системах, фактически провозглашая лишь общие принципы такой работы - справедливость, законность, оправданность, адекватность. При этом конкретные меры, которые надлежит принимать при сборе, обработке, хранении и передаче персональных данных в автоматизированных системах, отданы «на откуп» внутреннему законодательству каждого государства-участника Конвенции.

Следует обратить внимание также на условия, на которых то или иное государство может стать участником Конвенции. Несмотря на то, что в отношении положений Конвенции не может делаться никаких оговорок (ст. 25), ст. 3 Конвенции фактически допускает ее принятие с определенными заявлениями. Так, любое государство, желающее присоединиться к Конвенции, может правомерно заявить, что оно не будет применять Конвенцию к определенным категориям автоматизированных баз персональных данных. Кроме того, уже было названо ограничение (ст. 9) на осуществление прав на охрану и защиту персональных данных, содержащихся на электронных носителях и используемых в интересах защиты безопасности государства и общественной безопас- ности. Большинством из возможностей для принятия Конвенции с подобными заявлениями воспользовалась Российская Федерация.

\section{Влияние Конвенции на российское законодательство}

Обратимся к тексту Федерального закона от 19 декабря 2005 г. № 160-Ф3 «О ратификации Конвенции Совета Европы «О защите физических лиц при автоматизированной обработке персональных данных» ${ }^{8}$. В соответствии с названным Законом, Конвенция ратифицирована РФ со следующими заявлениями.

1. Российская Федерация заявляет, что в соответствии с подпунктом «а» пункта 2 статьи 3 Конвенции не будет применять Конвенцию к персональным данным:

а) обрабатываемым физическими лицами исключительно для личных и семейных нужд;

б) отнесенным к государственной тайне в порядке, установленном законодательством Российской Федерации о государственной тайне;

2. Российская Федерация заявляет, что в соответствии с подпунктом «с» пункта 2 статьи 3 Конвенции будет применять Конвенцию к персональным данным, которые не подвергаются автоматизированной обработке, если применение Конвенции соответствует характеру действий, совершаемых с персональными данными без использования средств автоматизации;

3. Российская Федерация заявляет, что в соответствии с подпунктом «а» пункта 2 статьи 9 Конвенции оставляет за собой право устанавливать ограничения права субъекта персональных данных на доступ к персональным данным о себе в целях защиты безопасности государства и общественного порядка.

Практически не вызывает вопросов пункт 2 Закона. Его содержание может рассматриваться как продиктованное соображениями элементарной логики: если Конвенция посвящена охране только тех персональных данных, которые подвергаются автоматизированной обработке, то оправданно полагать, что ее положения не могут распространяться на персональные данные, обрабатывающиеся иными способами. Однако следует отметить, что это не снимает ответственности с лиц, занимаю-

\footnotetext{
${ }^{8}$ Федеральный закон № 160-Ф3 «О ратификации Конвенции Совета Европы»
} 
щихся такими «иными» способами обработки персональных данных. Следовательно, работа над совершенствованием внутреннего законодательства России о правовом режиме персональных данных должна продолжаться - с главным ориентиром на соблюдения провозглашенных Конституцией РФ основных прав и свобод человека.

Касательно пункта 1 Закона, на наш взгляд, невозможно не отметить ряда особенностей данных, используемых человеком «исключительно для личных и семейных нужд». Все чаще мы прибегаем к электронным средствам для хранения подобных сведений: это и персональные компьютеры, и переносные электронные устройства для хранения данных, и мобильные телефоны. И все реже мы, не только в профессиональной деятельности, но и в повседневной жизни, не можем обойтись без средств электронных коммуникаций с целью межличностного общения. Практически любое электронное устройство, используемое для хранения, обработки и передачи информации, на сегодняшний день имеет возможность выхода в среду глобальных информационных сетей. С учетом того, что правовое регулирование отношений в таких сетях, прежде всего с технической точки зрения, в России развито крайне слабо, информация, хранящаяся на электронном носителе, связанном с глобальной информационной сетью, быстро становится «легкой добычей» для лиц, осуществляющих к ней несанкционированный доступ. Это происходит при полном, в соответствии с принятым Федеральным законом, отсутствии средств защиты. Так что в отношении подобных сведений единственным способом защиты остается «личная система приоритетов» гражданина в отношении сведений, которыми он обладает - в его интересах остается хранение информации, разглашение которой для него нежелательно, на носителях, максимально недоступных третьим лицам.

В отношении неприменения Конвенции к сведениям, составляющим государственную тайну, а также в отношении пункта 3 Ф3 «О ратификации Конвенции...» представляется возможным отметить достаточно широкое поле для злоупотребления подобным правом. Так, перечень сведений, составляющих государственную тайну, установлен одноименным Федеральным законом - следовательно, при соблюдении установленной законом процедуры такой перечень может быть и пересмотрен, и расширен. Теоретически к госу- дарственной тайне со временем может быть отнесена любая информация. Любые же персональные данные могут быть законодательно отнесены к сведениям, играющим значительную роль для обеспечения государственной безопасности и общественного порядка.

Российская Федерация также не говорит ничего о предусмотренных в статье 9 ограничениях Конвенции в различных неординарных ситуациях, к примеру, наложении ограничений на положения Конвенции для обеспечения безопасности не на государственном, а на локальном уровне. На предприятиях зачастую хранятся существенные объемы персональных данных, которые, по сути законодательства, нельзя использовать для предотвращения преступления как внутри предприятия, так и вне его. К таким субъектам относятся крупные государственные корпорации, валютно-кредитные организации и т.д. Таким образом, пробелы в законодательстве, расставление акцентов на формальное соблюдение закона, а не на истинные демократические ценности приводят к злоупотреблению правом и, напротив, невозможности применения необходимых знаний для предотвращения преступлений.

\section{Заключение}

Подводя итог, нельзя не отметить положительный шаг России к принятию и использованию прогрессивного европейского опыта организации автоматизированной обработки персональных данных. Однако в данном случае эффективность реализации норм Конвенции будет целиком зависеть от смысла изменений и дополнений внутреннего законодательства нашей страны, вызванного ратификацией Конвенции. Ф3 «О персональных данных» вызвал на практике огромное недоумения в техническом плане, так как 90\% субъектов оказались не готовы привести реализацию и хранение персональных данных в соответствие с Законом. Поэтому отдельные его положения сначала должны были быть введены до 2010 года, а потом и вовсе забылись. Таким образом, нормы Конвенции будут работать в России правомерно и эффективно только в том случае, если указанные изменения внутреннего законодательства будут основаны на провозглашенных Конвенцией принципах справедливости, адекватности и оправданности не интересами отдельных групп лиц, а подлинными демократическими ценностями, необходимостью защиты и охраны прав и свобод человека. 


\section{Национальная безопасность $1(24) \cdot 2013$}

\section{Библиография:}

1. Конституция РФ

2. Конвенция Совета Европы о защите физических лиц при автоматизированной обработке персональных данных

3. Федеральный закон от 19 декабря 2005 г. N 160-Ф3 «О ратификации Конвенции Совета Европы о защите физических лиц при автоматизированной обработке персональных данных»

4. Федеральный закон от 27 июля 2007 г. № 152-Ф3 «О персональных данных»

5. Олег Слепов «Защита персональных данных»/ Jet Info №5
6. Алексей Волков; Персональные данные: от Европы до России/ibusiness

7. Сахно А. Кому и зачем нужны системы электронного документооборота// Журнал «Компаньон Онлайн».

\section{References (transliteration):}

1. Oleg Slepov «Zashhita personal'nyh dannyh»/Jet Info №5

2. Aleksej Volkov; Personal'nye dannye: ot Evropy do Rossii/ibusiness

3. Sahno A. Komu i zachem nuzhny sistemy jelektronnogo dokumentooborota// Zhurnal «Kompan'on Onlajn». 